\title{
A TECHNIQUE FOR ESTIMATING THE BONE MARROW CELLULARITY IN VIVO USING ${ }^{59} \mathrm{Fe}^{*}$
}

\author{
BY \\ H. D. SUIT \\ From the Department of Radiotherapy, Oxford
}

(RECEIVED FOR PUBLICATION NOVEMBER 1,1956 )

This is a preliminary note on an attempt to develop a technique for estimating the bone marrow cellularity in man. At present there is no means of making such an estimate, and discussions of the probably mitotic interval and bone marrow life span of the different stages of erythrocyte precursors are based on calculations of the known average red cell life, the total numbers of red cells and reticulocytes in the peripheral blood, and the relative numbers and mitotic indices of the different erythrocyte precursors.

\section{Principle of the Method}

The method is based on the assumption that essentially all of the ${ }^{59} \mathrm{Fe}$ which appears in the peripheral erythrocytes after injection of the isotope has come from the bone marrow, except for that taken up directly by the reticulocytes in the peripheral blood.

Radioactive iron $\left({ }^{50} \mathrm{Fe}\right)$, after an intravenous injection, is rapidly cleared from the plasma (half clearance time is $90-120$ minutes), mainly by the bone marrow (Huff, Hennessy, Austin, Garcia, Roberts, and Lawrence, 1950). By 12 or 24 hours after the injection only a small percentage of the injected ${ }^{59} \mathrm{Fe}$ is in the peripheral erythrocytes, and there is essentially none in the plasma; the radioactivity found in a bone marrow sample collected at that time is due largely to the ${ }^{59} \mathrm{Fe}$ in the erythrocyte precursors of the marrow sample. From a nucleated cell count, a differential count, and radioactivity assay of the marrow sample, the ratio of erythrocyte precursors to radioactivity can be established. The appearance of the ${ }^{59} \mathrm{Fe}$ in the peripheral blood is followed in daily blood samples; after eight days there is usually no significant further increase. The proportion of the injected dose appearing in the peripheral blood by the eighth day is taken to be the same as that taken up directly by the marrow

* This work is part of a project supported by a full grant from the British Empire Cancer Campaign. after the injection. On this basis, the portion of the dose in the marrow at 24 hours would be that which went into the marrow at 0 hours, minus that which had already appeared in the blood. From this the total marrow cellularity can be estimated from the ratio, radioactivity of marrow sample/cellularity of marrow sample $=$ radioactivity of the total marrow/ cellularity of the total marrow.

Some attention has been given to the assumptions made in the use of this method. First, that of the order of $80 \%$ of the ${ }^{59} \mathrm{Fe}$ that is cleared from the plasma is taken up directly into the erythrocyte precursors and that it will appear in the blood over the following eight days. Huff et al. (1950) found that the increase in the radioactivity of human bone marrow (sacral) in vivo after a ${ }^{59} \mathrm{Fe}$ injection was the inverse of the fall of activity of the plasma. Similar observations have been made on rabbit bone marrow where the bone was excised and the radioactivity of the marrow determined directly (Huff et al., 1950). Autoradiographs prepared on rabbit bone marrow and peripheral blood after an injection of ${ }^{59} \mathrm{Fe}$ indicated that as the number of peripheral erythrocytes containing radioactive iron increased there was a fall in the isotope content of the bone marrow normoblasts (Suit, Lajtha, Oliver, and Ellis, 1957). The second assumption is that the bone marrow sample studied is a true representative of the marrow throughout the body. Rekers and Coulter (1948) in a detailed study found that bone marrow samples collected from ribs, femora, humeri, and tibae of adult dogs all had the same distribution of nucleated cells, although the cellularity of the specimens varied greatly. Presumably morphologically similar cell populations have the same functional activity. The third assumption is that the radioactivity of the reticulocytes in the bone marrow samples is the same as that in the peripheral blood. That is, that the reticulocytes of the marrow preparation (collected as 5-8 $\mathrm{ml}$. volume) are of the same relative number and age distribution as those 
of the peripheral blood. Comparisons of the number of reticulocytes in bone marrow particles and peripheral blood have given a ratio of about $2-4: 1$ (Ungricht, 1938; Seip, 1953). In three cases of the study for this report, reticulocyte counts were made on the bone marrow preparation and on the peripheral blood; the results were 0.6 and 0.7 ; 0.7 and 0.6 ; and 1.4 and $1.2 \%$ for the marrow and blood respectively (based on counts of 1,000 cells in each instance). These data do not demonstrate a difference. However, even if the reticulocyte level of the marrow were four times that of the peripheral blood, if the marrow was diluted by only a factor of 10 , the ratio of the marrow preparation : peripheral blood reticulocyte level would be $1.3: 1$. Seip (1953) in 13 cases compared the number of erythrocytes with the number of nucleated marrow cells in bone marrow particles and found a range of 12 to $43: 1$. The same comparison in the six cases presented here gave a range of 106 to $443: 1$. The reason for this difference is that in the method described here the marrow sample is greatly diluted with peripheral blood, which has the advantage of more accurate volume determination as well as dilution of marrow reticulocytes. These data would suggest that the bone marrow preparations as used in these total cellularity estimations contained at most 40 to $50 \%$ more reticulocytes than the peripheral blood. An increase of $50 \%$ in the radioactivity of the non-nucleated red cells of the marrow preparation would probably be more than correct for the greater number of reticulocytes in the marrow preparation, even though some of those were young reticulocytes with a high iron uptake. Autoradiography studies in rabbits showed $20 \%$ higher average grain counts over marrow reticulocytes than over blood reticulocytes. However, even if radioactivity in the erythrocytes in the marrow preparation were corrected by this factor of $50 \%$, it would not increase the final value for the cellularity by more than $20 \%$ (no such corrections are made on any of the following data presented).

A final assumption is that there is no death of the erythrocyte precursors of the bone marrow; that is, all of the nucleated erythrocyte precursors that take up the ${ }^{59} \mathrm{Fe}$ do mature and are released into the peripheral blood. Giblett, Coleman, Pirzio-Biroli, Donohue, Motulsky, and Finch (1956) have presented evidence to suggest that in certain varieties of anaemia some of the normoblasts do not mature into erythrocytes, and have referred to this as " ineffective erythropoiesis." Whether or not this process occurs to a measurable extent in the normal marrow is unknown. If it is a quantitatively small process normally, then its effect on the results of $\overrightarrow{\vec{F}^{\prime}}$ cellularity estimation would be to underestimate theo value, probably not more than $10 \%$ (as $80 \%$ or more음 of the injected ${ }^{59} \mathrm{Fe}$ is considered to be in the normo- $\overline{\bar{c}}$. blasts at the time of measuring the activity of the marrow sample).

\section{Sample Calculation (Experiment 1011)}

${ }^{59} \mathrm{Fe}$ was injected on May 24, 1955 (this is equivalent $\vec{\omega}$ to a total count rate of $3.79 \quad 10^{5} \mathrm{cpm}$.). Bone marrow was collected on May 25.

1. Radioactivity of $10 \mathrm{ml}$. bone marrow preparation $\overrightarrow{0}$ due to erythrocyte precursors:

(a) Total radioactivity of the sample $=47 \mathrm{cmm}$.

(b) Red cell count of the sample $=2.72 \quad 10^{10}$

R.B.C.' $10 \mathrm{ml}$.

(c) Activity of $10 \mathrm{ml}$. peripheral blood $=25 \mathrm{cpm} .-$ R.B.C. in $10 \mathrm{ml}$. peripheral blood $=5.4 \times 10^{10}$ R.P.C. $\therefore 2.72 \times 10^{10}$ R.B.C. would have $12 \mathrm{cpm}$.

(d) Activity of the marrow preparation due to

${ }^{59} \mathrm{Fe}$ in the erythrocyte precursors: $47-12=35 \mathrm{cpm}$.

2 . Bone marrow sample cellularity

10,600 nucleated cells per $\mathrm{mm}^{3}=$

$1.06 \times 10^{8}$ nucleated cells in $10 \mathrm{ml}$.

3. Total radioactivity of the bore marrow.

(a) Percentage of the injected dose that went directly into the erythrocyte precursors $=100 \%$.

(b) Activity in erythrocyte precursors on May $25 \AA$

$=$ total ${ }^{59} \mathrm{Fe}$ injected $-{ }^{59} \mathrm{Fe}$ in peripheral blcod on $\overrightarrow{\vec{P}}$

May 25.

$=$ total counts injected $-(\mathrm{cpm} . \mathrm{ml}$. whole blood

blood volume)

$=3.79 \cdot 10^{5}-2.5 \cdot 4,700$

$=3.79 \cdot 10^{5}-0.11 \cdot 10^{5}$

$=3.68 \quad 10^{5} \mathrm{cpm}$.

4. Total number of bone marrow nucleated cells marrow sample cellularity whole bone marrow activity

$=\frac{1.06 \div \frac{10^{8} \cdot 3.68}{3.5} 10^{1}}{1.5} 0^{5}$
$=1.11 \therefore 10^{12}$ nucleated cells.

5. Bore marrow differential count

$14 \%$ of the total nucleated cells are erythrocyte precursors

$\therefore$ total number of erythrocyte precursors

$15.4 \times 10^{10}$.

\section{Discussion}

Results from such studies of six patients are $\frac{0}{0}$ presented in Table I. There is a wide range (6 to 24 ब

$10^{10}$ ) in the estimated total number of erythrocyte $\frac{\rho}{\mathbb{N}}$ precursors. The range for five cases was 10 to $\varrho$ $24 \times 10^{10}$ cells. These data when compared with the probable daily erythrocyte production indicate ao 
short life span in the bone marrow for the normoblasts, i.e., less than one day.

The most likely source of error is the allowance for the radioactivity in the erythrocytes (reticulocytes) of the marrow preparation. As the reticulocytes of the marrow are younger and have a higher iron uptake than those of the peripheral blood the calculated result is an under-estimate of the total cellularity.

TABLE I

TOTAL MARROW CELLULARITY

\begin{tabular}{c|c|c|c}
\hline $\begin{array}{c}\text { Experiment } \\
\text { No. }\end{array}$ & $\begin{array}{c}\text { Total Marrow } \\
\text { Nucleated } \\
\text { Red Cells } \\
\times 10^{10}\end{array}$ & $\begin{array}{c}\text { Total Body } \\
\text { Erythrocytes } \\
\times 10^{10 *}\end{array}$ & $\begin{array}{c}\text { Erythrocyte } \\
\text { Production } \\
\text { Per Day } \\
\times 10^{10} \dagger\end{array}$ \\
\hline 1006 & 24 & 2,680 & 22 \\
1007 & 11 & 2,210 & 18 \\
1011 & 15 & 2,500 & 21 \\
1014 & 22 & 2,350 & 20 \\
1015 & 18 & 1,700 & 14 \\
1017 & 6 & 1,640 & 14 \\
\hline
\end{tabular}

* Product of blood volume and erythrocyte count. Blood volume was estimated from the ${ }^{50} \mathrm{Fe}$ determined plasma volume on a venous haematocrit.

+ On the basis of an averagelife span of 120 days.
Also the patients used for these studies, although in good general condition, nevertheless had malignant diseases which often result in a progressive anaemia. The figures presented in Table I are not, therefore, considered to represent normal values but probably values below normal. Osgood (1954) calculated the number of erythrocyte precursors in normal human marrow to be of the order of 40 to $60 \times 10^{10}$ cells.

This technique appears to offer an opportunity of estimating the marrow cellularity, but further experiments are needed to determine the radioactivity of the reticulocytes in the dilute bone marrow samples.

\section{REFERENCES}

Giblett, E. R., Coleman, D. H., Pirzio-Biroli, G., Donohue, D. M. Motulsky, A. G., and Finch, C. A. (1956). Blood, 11, 291.

Huff, R. L., Hennessy, T. G., Austin, R. E., Garcia, J. F., Roberts, B. M., and Lawrence, J. H. (1950). J. clin. Invest., 29, 1041. Osgood, E. E. (1954). Blood, 9, 1141.

Rekers, P. E., and Coulter, M. (1948). Amer. J. med. Sci., 216, 643.

Seip, M. (1953). Acta med. Scand., Suppl. 282.

Suit, H. D., Lajtha, L. G., Oliver, R., and Ellis, F. (1957). Brit. J. Haematol., 3, 165.

Ungricht, M. (1938). Folia haemat. (L.pz.), 60, 145. 